\title{
Silagem de peixe em ração artesanal para tilápia-do-nilo
}

\author{
Eduardo Gianini Abimorad(1), Wilson Luiz Strada(1), Sérgio Henrique Canelo Schalch ${ }^{(1)}$, \\ Fabiana Garcia(1), Daniela Castellani ${ }^{(1)}$ e Marcelo da Rocha Manzatto(2)
}

\begin{abstract}
(1)Agência Paulista de Tecnologia dos Agronegócios, Polo Regional do Noroeste Paulista, Caixa Postal 61, CEP 15500-970 Votuporanga, SP. E-mail: abimorad@apta.sp.gov.br, wstrada@ig.com.br, sschalch@apta.sp.gov.br, fgarcia@apta.sp.gov.br, daniela.castellani@apta.sp.gov.br (2)Piscicultura Estância dos Dourados, Rodovia Vicinal José Marciano Barreto, Km 5, CEP 15520-000 Valentim Gentil, SP. E-mail: mrmanzatto@gmail.com
\end{abstract}

Resumo - O objetivo deste trabalho foi avaliar o emprego de ração artesanal à base de silagem de resíduo da filetagem de pescado na criação de tilápia-do-nilo (Oreochromis niloticus). Dois mil e setenta juvenis de tilápia revertidos $(83,1 \mathrm{~g})$ foram distribuídos em seis viveiros escavados com $230 \mathrm{~m}^{2}$ cada um, na densidade de estocagem de 1,5 peixe por metro quadrado, em delineamento inteiramente casualizado com dois tratamentos (ração artesanal e ração comercial) e três repetições. Foram analisados os parâmetros de desempenho produtivo (sobrevivência, ganho em peso, conversão alimentar aparente, taxa de crescimento específico e coeficiente de variação do peso final), as variáveis de qualidade da água (oxigênio dissolvido, transparência e fósforo e nitrogênio total), o custo de arraçoamento e a composição corporal. Não houve diferença significativa entre as rações para os parâmetros de desempenho produtivo. Verificou-se maior eutrofização da água dos viveiros onde os peixes receberam ração artesanal. O custo por quilograma de peixe produzido com ração artesanal (R\$ 1,07$)$ foi aproximadamente $42 \%$ menor que o de peixe produzido com ração comercial $(\mathrm{R} \$ 1,86)$. Os peixes alimentados com ração artesanal tiveram teor de lipídios significativamente menor na carcaça.

Termos para indexação: Oreochromis niloticus, eutrofização, nutrição, silagem ácida.

\section{Fish silage in farm-made feed for Nile tilapia}

\begin{abstract}
The objective of this work was to evaluate the use of a farm-made feed based on silage of fish filleting residues for Nile tilapia (Oreochromis niloticus) farming. Two thousand and seventy masculinized tilapia juveniles $(83.1 \mathrm{~g})$ were distributed into six ponds $\left(230 \mathrm{~m}^{2}\right)$, at a stocking density of 1.5 fish per square meter. The experimental design was a completely randomized with two treatments (farm-made and commercial feeds) and three replicates. The performance parameters analyzed were survival, weight gain, apparent feed conversion, specific growth rate, and final weight coefficient of variation. The water quality variables analyzed were dissolved oxygen, transparency, and total phosphorus and nitrogen. Feeding cost and body composition were also evaluated. No significant differences were observed in the performance parameters. Water eutrophication in the ponds with farm-made feed was higher than in ponds with commercial feed. The cost of fish produced using farm-made feed $\left(\mathrm{R} \$ 1.07 \mathrm{~kg}^{-1}\right)$ was approximately $42 \%$ lower than the cost of fish produced using commercial feed $\left(\mathrm{R} \$ 1.86 \mathrm{~kg}^{-1}\right)$. Fish fed with farm-made feed had lower lipid body content than fish fed with commercial feed.
\end{abstract}

Index terms: Oreochromis niloticus, eutrophication, nutrition, acid silage.

\section{Introdução}

A aquicultura tem participado cada vez mais da produção pesqueira mundial, principalmente devido à redução dos estoques naturais e ao aumento da demanda por alimentos mais saudáveis (Valenti et al., 2000; Food and Agriculture Organization of the United Nations, 2004). Atualmente, a tilápia (Oreochromis niloticus) é uma espécie de grande interesse no mercado mundial devido à ausência de espinhas no filé e à carne de excelente sabor (Silva, 1999).

Houve um grande avanço tecnológico em relação a melhoramento genético, biologia, reprodução, prevenção de doenças, nutrição e manejo na criação de tilápias (El-Sayed, 1999). No Brasil, a principal dificuldade na produção de tilápias é uma nutrição adequada, aliada ao manejo alimentar correto, já que os gastos com alimentação chegam a atingir $65 \%$ do custo total de produção (Firetti $\&$ Sales, 2004). O uso de rações artesanais, de custo acessível, pode ser vantajoso, visto que a margem de lucro é pequena.

Além de ter maior poder de compra, as indústrias de ração utilizam matérias-primas de boa qualidade para a fabricação de rações para peixes, que, na maioria das vezes, são extrusadas para facilitar o controle do consumo.

Pesq. agropec. bras., Brasília, v.44, n.5, p.519-525, maio 2009 
A utilização de rações artesanais possibilita ao piscicultor incluir na dieta um ou mais ingredientes disponíveis na propriedade rural ou em sua região, a um baixo custo. Em países em desenvolvimento, é comum o uso de rações feitas na propriedade utilizando ou não silagem de peixe como ingrediente (New et al., 1994). Porém, o valor nutricional desse tipo de dieta é variável (Fagbenro \& Jauncey, 1998), e sua eficiência tem sido pouco avaliada.

A silagem de pescado é fonte de minerais, ácidos graxos e proteína de alta qualidade. É um alimento bastante versátil, que pode ser utilizado como suplemento em rações para vários animais, como peixes, suínos, aves, ovelhas e gado (Haard et al., 1985). É, também, uma das formas de aproveitamento dos resíduos da produção, industrialização e comercialização do pescado, os quais constituem matéria-prima de alta qualidade e cujo aproveitamento na forma de silagem é ecologicamente recomendável, em razão da alta quantidade de matéria orgânica que é descartada no ambiente quando esses resíduos não são aproveitados (De Arruda et al., 2007).

A tecnologia de obtenção da silagem é simples, não implica utilização de maquinários específicos. Necessita apenas de triturador e recipientes de plástico (silos) e não exige mão de obra especializada. O ensilado de pescado é um processo conhecido há muito tempo e consiste basicamente em acidificar a massa triturada, deixando-a livre da ação das enzimas próprias dos tecidos e de microrganismos patogênicos, que terminam deteriorando o produto (Tatterson \& Windsor, 1974). A acidificação da silagem pode ser obtida pela adição de ácidos minerais ou orgânicos ou pelo uso de microrganismos produtores de ácido lático.

A aquicultura, assim como outras atividades agropecuárias, pode ser poluidora do ambiente, por meio da degradação da qualidade da água dos corpos receptores. A principal causa do enriquecimento da água proveniente de viveiros de piscicultura são as substâncias dissolvidas ou em suspensão. Essas substâncias são provenientes de excretas e sobras de ração, que são convertidas em materiais orgânicos, dióxido de carbono, nitrogênio amoniacal, fosfatos e outros compostos (Montoya et al., 2000). A aquicultura moderna está embasada em três pilares: a produção lucrativa, a preservação do ambiente e o desenvolvimento social (McCausland et al., 2006).
O objetivo deste trabalho foi avaliar o emprego de uma ração artesanal à base de silagem de resíduo da filetagem de pescado na criação de tilápia-do-nilo.

\section{Material e Métodos}

O experimento foi conduzido em propriedade particular localizada em Valentim Gentil, SP (20²2'28"S; 505'36"W), no período de 15/5/2007 a 23/10/2007.

Foram selecionados 2.070 juvenis de tilápia-do-nilo revertidos sexualmente para machos, com peso médio inicial de 83,1 g. Os animais foram distribuídos em seis viveiros escavados, com aproximadamente $230 \mathrm{~m}^{2}$ cada, com profundidade média de $1,1 \mathrm{~m}$, numa densidade de estocagem de 1,5 peixe por metro quadrado. $\mathrm{O}$ experimento foi conduzido em delineamento inteiramente casualizado, com dois tratamentos (ração comercial extrusada e ração artesanal à base de silagem de peixe) e três repetições. Os viveiros foram abastecidos diariamente com água bombeada de uma represa e drenados individualmente por meio de monges. O sistema foi considerado praticamente estático, visto que os viveiros sofriam perdas de água por infiltração e evaporação e pouca água era drenada pelos monges.

A silagem utilizada na ração experimental foi confeccionada na propriedade, com resíduos triturados da filetagem de zoiudo (Geophagus surinamensis) adquiridos em uma peixaria. A massa gerada após a trituração dos resíduos foi pesada e acondicionada em caixas d'água de polietileno (300 L). A essa massa foram adicionados os ácidos sulfúrico e fórmico, na proporção de $1 \%$ cada e, a seguir, a mistura foi homogeneizada manualmente com auxílio de um bastão de madeira, uma vez ao dia, durante sete dias. A mistura foi ensilada por um período mínimo de 30 dias antes de ser utilizada na confecção da ração.

A ração artesanal foi composta por silagem úmida de peixe, farelo de soja, farelo de algodão e milho moído (Tabela 1). O pH da silagem foi neutralizado com calcário e, posteriormente, os outros ingredientes moídos foram misturados à silagem em uma betoneira. Em seguida, a ração foi fornecida úmida (aproximadamente $49 \%$ de umidade), sem processamento, na proporção de $1,8 \mathrm{~kg}$ para cada $1 \mathrm{~kg}$ de ração extrusada $(89 \%$ de matéria seca). A oferta foi calculada com base em percentagem da biomassa, segundo uma tabela de arraçoamento, dividida em três alimentações diárias. 
Para o cálculo do custo da silagem, foram considerados a taxa da licença para aquisição dos ácidos, a compra dos ácidos, o frete de um automóvel utilitário para buscar os resíduos do pescado em uma peixaria de Votuporanga, SP (a $27 \mathrm{~km}$ da propriedade), a mão de obra, a energia elétrica utilizada pelo triturador, a depreciação [(preço de compra - valor residual)/vida útil] do triturador e a depreciação das caixas d'água de polietileno para armazenagem da silagem.

O oxigênio dissolvido, a temperatura e a transparência da água foram mensurados semanalmente, por volta das $8 \mathrm{~h}$, utilizando um oxímetro YSI 55 e disco de Secchi. Amostras de água de abastecimento e efluente dos viveiros foram coletadas no início, meio e final do experimento (1 $1^{\mathrm{a}}, 13^{\mathrm{a}}$ e $23^{\mathrm{a}}$ semanas), em garrafas de plástico de $500 \mathrm{~mL}$, que foram imediatamente congeladas para posteriores análises de nitrogênio e fósforo total, utilizadas para o cálculo do balanço (efluente-abastecimento) desses nutrientes.

Após a biometria final e o controle do consumo de ração, os seguintes parâmetros foram mensurados: sobrevivência $=100$ (número de peixes despescados/ número de peixes povoados); ganho em peso, $\mathrm{GP}=$ peso médio final - peso médio inicial; conversão alimentar aparente, $\mathrm{CAA}=$ consumo de alimento/ganho em peso; taxa de crescimento específico, TCE $=100\left(\log _{\mathrm{e}}\right.$ peso final - $\log _{\mathrm{e}}$ peso inicial)/tempo; coeficiente de variação do peso final, $\mathrm{CVP}=100$ (desvio-padrão do peso final/peso médio final) e custos de arraçoamento $=\mathrm{CAA} \times$ preço da ração.

Para determinação da composição corporal, dez peixes inteiros de cada viveiro foram coletados aleatoriamente no final do experimento, sacrificados por superdosagem de anestésico (benzocaína) e moídos em moedor de carne. As amostras moídas foram armazenadas em freezer para posteriores análises laboratoriais.

As análises bromatológicas dos alimentos e da carcaça dos peixes foram realizadas segundo a Association of Official Analytical Chemists (2000) no Laboratório de Nutrição de Organismos Aquáticos do Centro de Aquicultura da Universidade Estadual Paulista (Caunesp), Campus de Jaboticabal, SP. As análises de nitrogênio e fósforo total das amostras de água coletadas foram realizadas segundo as metodologias de Mackereth et al. (1978) e Golterman et al. (1978), respectivamente, no Laboratório de Ecologia Aquática do Caunesp, Campus de Rio Claro, SP.

As médias dos parâmetros de desempenho produtivo, composição corporal e das variáveis limnológicas foram submetidas ao teste $t$ de Student, a 5\% de probabilidade, com igual variância (Mendes, 1999). Os valores da sobrevivência, expressos em percentagens (x), foram submetidos à transformação de arc sen $(\mathrm{x} / 100)^{0,5}$ (Mendes, 1999). Os dados foram analisados no programa SAS (SAS Institute, 2002). As médias de temperatura, oxigênio dissolvido, transparência, nitrogênio e fósforo total da água para os dois tratamentos estão apresentadas na forma de gráficos em função do tempo.

\section{Resultados e Discussão}

Não houve diferença significativa $(p>0,05)$ entre os tratamentos para os parâmetros de desempenho avaliados (Tabela 2). $\mathrm{O}$ custo de arraçoamento variou

Tabela 1. Composição das rações experimentais e dos ingredientes utilizados na formulação da ração artesanal.

\begin{tabular}{|c|c|c|c|c|c|c|c|}
\hline Composição proximal (\%) & $\begin{array}{c}\text { Ração } \\
\text { artesanal }^{(2)}\end{array}$ & $\begin{array}{c}\text { Ração } \\
\text { comercial }\end{array}$ & $\begin{array}{l}\text { Silagem } \\
\text { de peixe }\end{array}$ & $\begin{array}{c}\text { Farelo de } \\
\text { algodão }\end{array}$ & $\begin{array}{l}\text { Farelo } \\
\text { de soja }\end{array}$ & Milho & Calcário \\
\hline Matéria seca (MS) & 48,8 & 89,0 & 20,0 & 88,0 & 89,9 & 88,5 & 89,0 \\
\hline Proteína bruta $(\mathrm{PB})$ & 15,3 & 28,0 & 6,6 & 38,8 & 45,4 & 8,4 & 0,0 \\
\hline Extrato etéreo (EE) & 4,8 & 3,0 & 6,5 & 1,8 & 2,0 & 4,0 & 0,0 \\
\hline Fibra bruta (FB) & 3,0 & 8,0 & 0,0 & 1,2 & 7,6 & 2,2 & 0,0 \\
\hline Extrativo não nitrogenado (ENN) & 19,0 & 40,0 & 1,4 & 29,4 & 28,8 & 72,6 & 0,0 \\
\hline Matéria mineral (MM) & 6,7 & 10,0 & 5,5 & 6,2 & 6,1 & 1,3 & 89,0 \\
\hline Cálcio (Ca) & 1,33 & 1,80 & 0,99 & 0,24 & 0,32 & 0,04 & 34,2 \\
\hline Fósforo (P) & 0,50 & 0,60 & 0,72 & 0,34 & 0,19 & 0,08 & 0,0 \\
\hline Energia bruta $\left(\mathrm{kcal} \mathrm{kg}^{-1}\right)^{(3)}$ & 2.226 & 3.813 & 1.039 & 3.630 & 4.263 & 3.953 & 0,0 \\
\hline Preço $\left(\mathrm{R} \$ \mathrm{~kg}^{-1}\right)$ & 0,34 & 1,02 & 0,11 & 0,76 & 0,90 & 0,51 & 0,14 \\
\hline
\end{tabular}


de $\mathrm{R} \$ 1,83$ a $\mathrm{R}$ \$1,89 para os peixes alimentados com ração comercial e de $\mathrm{R} \$ 1,03$ a $\mathrm{R} \$ 1,17$ para os peixes alimentados com ração artesanal, podendo-se observar uma redução média de $\mathrm{R} \$ 0,78$ por quilograma de peixe produzido, que representa aproximadamente $42 \%$ de economia.

Ao avaliar o desempenho de tilápias alimentadas com dietas com diferentes níveis de silagem de peixe em substituição à ração comercial, Carvalho et al. (2006) também não encontraram diferenças para os parâmetros de desempenho produtivo, contudo, observaram efeito linear decrescente para custo com alimentação. Assano (2004) observou somente menor custo de arraçoamento com dietas à base de silagem de peixe em relação às dietas à base de farinha de peixe e farelo de soja, sem prejuízo para o crescimento de tilápias criadas em viveiro escavado. Oliveira et al. (2006) não observaram diferença no desempenho de tilápias submetidas a diferentes níveis de substituição da farinha de peixes por silagem de peixe. Por essa razão, a silagem de peixe apresenta-se como alimento alternativo de baixo custo para tilápias, podendo ser utilizada principalmente em rações artesanais.

Não houve diferença entre os tratamentos para umidade, proteína e cinzas $(\mathrm{p}>0,05)$ (Tabela 2$)$. O teor médio de lipídios dos peixes alimentados com ração artesanal foi significativamente menor que o dos alimentados com ração comercial, o que pode proporcionar maior rendimento de filé. Isso pode estar relacionado ao fato de que a tilápia utiliza melhor os lipídios que os carboidratos como fonte de energia, visto que a ração artesanal continha $8,8 \%$ de extrato etéreo e $34,7 \%$ de extrativo não nitrogenado, enquanto a ração comercial continha 3\% de extrato etéreo e $40 \%$ de extrativo não nitrogenado.
Apesar de a tilápia-do-nilo ser considerada onívora, seu hábito alimentar predominante é fitoplanctófago (Hassan et al., 1997). Os plânctons, em sua composição, são pobres em carboidratos. Assim, a ingestão de carboidratos na alimentação natural da tilápia, principalmente na forma de amido, é muito pequena. Dessa forma pode-se deduzir que a sua capacidade para digerir esse tipo de nutriente é baixa em comparação à capacidade para digerir lipídios. Os lipídios são fontes imediatas de energia e de ácidos graxos essenciais para a maioria das espécies de peixes, e estão presentes em grande quantidade nos organismos planctônicos (Sipaúba-Tavares \& Rocha, 2003).

Winfree \& Stickney (1981), El-Sayed \& Teshima (1992) e Wang et al. (2005) correlacionaram a maior concentração de lipídio corporal com o aumento nas concentrações de amido na dieta, em tilápias. Toledo (2004) constatou que tilápias alimentadas com dietas com 6 ou $9 \%$ de extrato etéreo apresentaram maior ganho de peso que com dieta contendo 3\% de extrato etéreo. Carvalho et al. (2006) não observaram diferença no desempenho de tilápias alimentadas com ração comercial acrescida de silagem de peixes, as quais apresentaram variação de 6 a 10,4\% de extrato etéreo. De acordo com Boscolo et al. (2004), houve relação linear entre o teor de extrato etéreo $(1,9$ a 5,9\%) na dieta e o rendimento de filé de tilápias, sem afetar a percentagem de gordura do filé e o desempenho dos peixes. Isso sugere que a relação carboidrato/lipídios na ração artesanal, assim como sua composição em ácidos graxos, pode estar mais adequada às necessidades nutricionais das tilápias.

Tabela 2. Desempenho produtivo e composição corporal de tilápias-do-nilo alimentadas com ração artesanal à base de silagem de peixe e ração comercial em viveiros escavados ${ }^{(1)}$.

\begin{tabular}{|c|c|c|c|c|}
\hline Parâmetros $^{(2)}$ & Ração comercial & Ração artesanal & Valor de $\mathrm{p}$ & CV $(\%)$ \\
\hline \multicolumn{5}{|c|}{ Desempenho produtivo } \\
\hline Peso inicial $(\mathrm{g})$ & $82,55 \pm 2,55 \mathrm{a}$ & $83,57 \pm 1,56 a$ & $0,7486^{\text {ns }}$ & 4,41 \\
\hline Peso final (g) & $384,12 \pm 4,70 \mathrm{a}$ & $399,23 \pm 9,07 a$ & $0,2134^{\mathrm{ns}}$ & 3,20 \\
\hline Sobrevivência (\%) & $88,82 \pm 1,72 \mathrm{a}$ & $90,76 \pm 1,19 \mathrm{a}$ & $0,4065^{\mathrm{ns}}$ & 3,34 \\
\hline Consumo $(\mathrm{g})$ & $554,62 \pm 9,07 \mathrm{a}$ & $550,22 \pm 12,61 \mathrm{a}$ & $0,7912^{\text {ns }}$ & 3,44 \\
\hline GP $(g)$ & $304,30 \pm 6,15 \mathrm{a}$ & $320,17 \pm 10,10 \mathrm{a}$ & $0,2511^{\mathrm{ns}}$ & 4,64 \\
\hline CAA & $1,82 \pm 0,02 \mathrm{a}$ & $1,72 \pm 0,08 \mathrm{a}$ & $0,2779^{\mathrm{ns}}$ & 5,51 \\
\hline TCE (\% por dia) & $1,06 \pm 0,01 \mathrm{a}$ & $1,07 \pm 0,02 \mathrm{a}$ & $0,4713^{\text {ns }}$ & 2,67 \\
\hline CVP (\%) & $9,65 \pm 1,23 \mathrm{a}$ & $6,91 \pm 0,28 \mathrm{a}$ & $0,0956^{\mathrm{ns}}$ & 18,64 \\
\hline \multicolumn{5}{|c|}{ Composição corporal ( $\mathrm{g}$ por $100 \mathrm{~g}$ de amostra úmida) } \\
\hline Umidade & $68,74 \pm 0,52 \mathrm{a}$ & $67,31 \pm 0,23 \mathrm{a}$ & $0,0657^{\mathrm{ns}}$ & 1,02 \\
\hline Proteína & $18,01 \pm 0,32 \mathrm{a}$ & $17,54 \pm 0,34 \mathrm{a}$ & $0,3755^{\text {ns }}$ & 3,20 \\
\hline Lipídios & $9,30 \pm 0,26 \mathrm{a}$ & $6,46 \pm 0,28 b$ & $0,0017 * *$ & 5,91 \\
\hline Cinzas & $5,55 \pm 0,29 \mathrm{a}$ & $4,92 \pm 0,03 \mathrm{a}$ & $0,1595^{\mathrm{ns}}$ & 6,74 \\
\hline
\end{tabular}

${ }^{(1)}$ Médias \pm erro-padrão seguidas de letras iguais, na linha, não diferem entre si pelo teste t, a $5 \%$ de probabilidade. ${ }^{(2)}$ GP, ganho de peso; CAA, conversão alimentar aparente; TCE, taxa de crescimento específico; CVP, coeficiente de variação do peso final. 
A partir da sétima semana, houve redução acentuada da transparência da água em ambos os tratamentos (Figura 1). Entretanto, os valores médios de transparência da água dos viveiros que receberam ração artesanal $(34,7 \pm 13 \mathrm{~cm})$ foram estatisticamente menores $(\mathrm{p}=0,0242)$ que os valores dos viveiros que receberam ração comercial $(41,1 \pm 27 \mathrm{~cm})$, o que indica possível eutrofização. Também foi observado que a água desses viveiros apresentava coloração esverdeada, um indicativo de excesso de fitoplâncton (Cremen et al., 2007), enquanto a água dos viveiros do tratamento com ração comercial apresentava coloração parda, provavelmente devido aos sólidos em suspensão. Isso pode ser outra explicação para o menor teor de lipídios na carcaça dos peixes que receberam a ração artesanal, pois as tilápias desse tratamento tiveram maior acesso ao alimento natural (excesso de fitoplâncton).

As concentrações médias de oxigênio dissolvido na água dos viveiros do tratamento com ração artesanal $\left(5,32 \pm 1,1 \mathrm{mg} \mathrm{L}^{-1}\right)$ foram significativamente menores $(\mathrm{p}=0,0415)$ que as do tratamento com ração comercial $\left(5,89 \pm 0,8 \mathrm{mg} \mathrm{L}^{-1}\right)$, e atingiu concentrações inferiores a $5 \mathrm{mg} \mathrm{L}^{-1}$ na $3^{\mathrm{a}}, 4^{\mathrm{a}}, 5^{\mathrm{a}}, 10^{\mathrm{a}}, 16^{\mathrm{a}}, 18^{\mathrm{a}}, 22^{\mathrm{a}}$ e $23^{\mathrm{a}}$ semana (Figura 2). Segundo a Resolução Conama no 357, de 2005 (Brasil, 2005), as concentrações de oxigênio dissolvido da água destinada à aquicultura não devem ser inferiores a $5 \mathrm{mg} \mathrm{L}^{-1}$. Dessa forma, o fornecimento da ração artesanal piorou a qualidade da água, indicando maior consumo de oxigênio dissolvido pela decomposição de matéria orgânica e respiração de algas durante a noite (Mires, 1995).

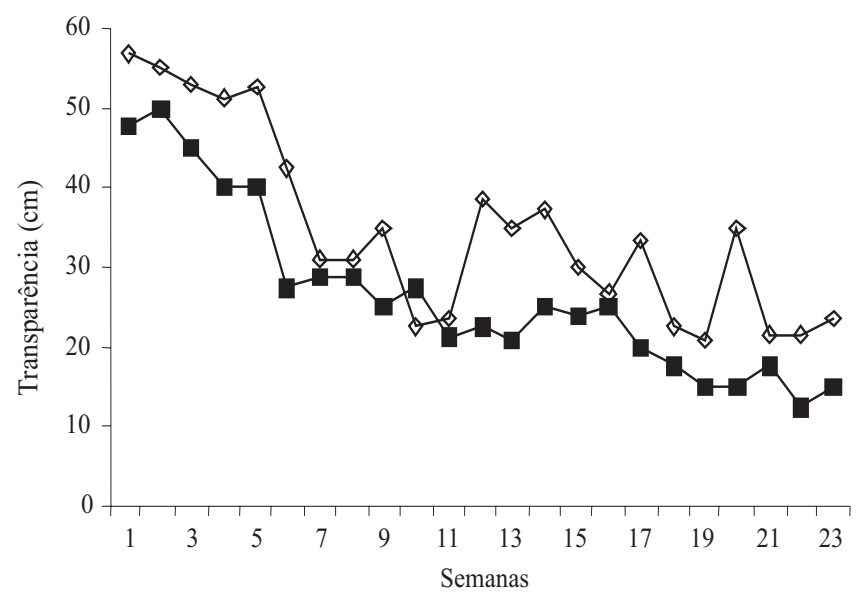

Figura 1. Transparência da água (cm) nos viveiros escavados de criação de tilápias-do-nilo alimentadas com ração artesanal à base de silagem de peixe (ロ) e ração comercial $(\diamond)$. Cada ponto representa a média de três viveiros.
No início do experimento (primeira semana), o balanço (efluente-abastecimento) de fósforo total na água encontrava-se próximo de zero (Figura 3) em ambos os tratamentos. Na $13^{\mathrm{a}}$ semana, o balanço de fósforo total na água do tratamento que recebeu ração comercial manteve-se baixo, enquanto o tratamento com ração artesanal teve aumento significativo, chegando

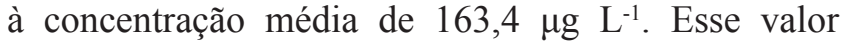
está acima do limite máximo permitido pela Resolução Conama nº 357, de 2005, para ambientes

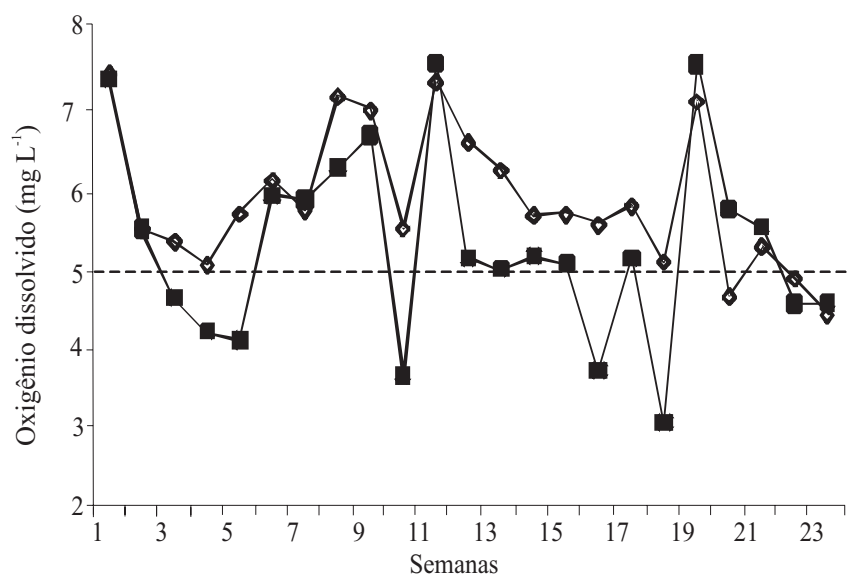

Figura 2. Oxigênio dissolvido $\left(\mathrm{mg} \mathrm{L}^{-1}\right)$ na água dos viveiros escavados de criação de tilápias-do-nilo, alimentadas com ração artesanal à base de silagem de peixe (๘) e ração comercial $(\diamond)$. Cada ponto representa a média de três viveiros. A linha pontilhada representa o limite mínimo (5 mg L ${ }^{-1}$ ) estabelecido pela Resolução Conama no 357 de 2005 (Brasil, 2005).

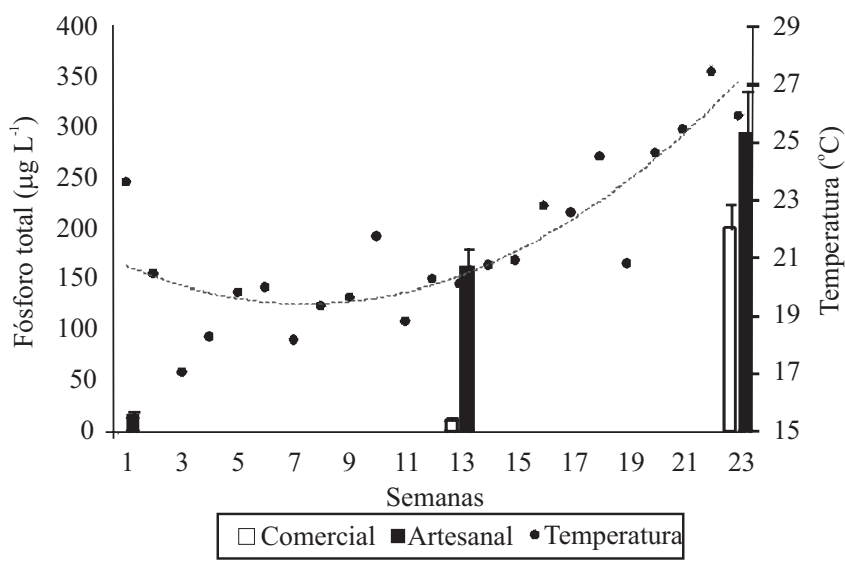

Figura 3. Balanço de fósforo total $\left(\mu \mathrm{g} \mathrm{L}^{-1}\right)$ na água dos viveiros escavados de criação de tilápias-do-nilo, alimentadas com ração artesanal à base de silagem de peixe $(\square)$ e ração comercial ( $\square$ ). Cada barra representa a média \pm erro-padrão de três viveiros. A linha pontilhada representa a tendência da temperatura da água. 
intermediários, que não deve ultrapassar $50 \mu \mathrm{g} \mathrm{L}^{-1}$. Ao final do experimento (23 $3^{\underline{a}}$ semana), o balanço de fósforo total apresentou aumento significativo em ambos os tratamentos, atingindo $202,1 \mu \mathrm{g} \mathrm{L}^{-1}$ no tratamento com ração comercial e $294 \mu \mathrm{g} \mathrm{L}^{-1}$ no tratamento com ração artesanal, os quais foram significativamente diferentes entre si $(p=0,0117)$.

Os balanços de nitrogênio total na água dos viveiros apresentaram comportamento semelhante aos do fósforo total (Figura 4), sendo significativamente diferentes entre si ao final do experimento $(p=0,0072)$. Isso deve estar relacionado ao maior aporte de nutrientes devido à maior oferta de alimento pelo crescimento dos peixes e ao aumento da temperatura da água que, consequentemente, aumentou o consumo de ração em ambos os tratamentos, a partir da 13로 semana.

Baccarin \& Camargo (2005) avaliaram quatro manejos alimentares para tilápias criadas em viveiros escavados (fertilização orgânica e rações farelada, peletizada e extrusada) e observaram o maior ganho em peso dos peixes que receberam ração peletizada, não diferenciando dos que receberam ração extrusada. No entanto, só encontraram maiores concentrações de fósforo total na água dos viveiros que foram fertilizados. A ração artesanal do presente trabalho não sofreu qualquer processamento. Os ingredientes secos foram misturados à silagem formando grumos úmidos, que foram fornecidos a lanço com o auxílio de uma pá. Essa estratégia de alimentação favoreceu a dissolução de nutrientes na água,

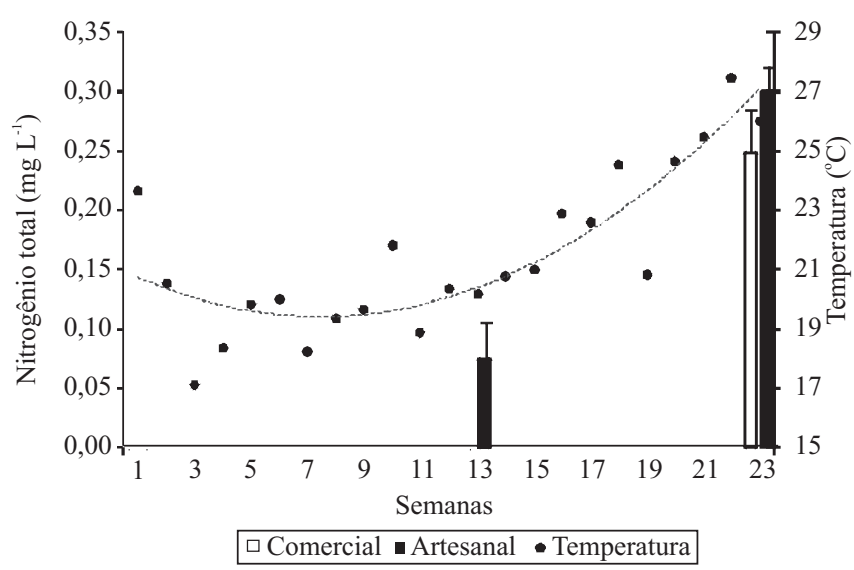

Figura 4. Balanço de nitrogênio total $\left(\mathrm{mg} \mathrm{L}^{-1}\right)$ na água dos viveiros escavados de criação de tilápias-do-nilo, alimentadas com ração artesanal à base de silagem de peixe (ロ) e ração comercial ( $\square$ ). Cada barra representa a média \pm erro-padrão de três viveiros. A linha pontilhada representa a tendência da temperatura da água. principalmente o fósforo, que também se encontrava em maior quantidade na ração artesanal $(0,92 \%)$ em relação à ração comercial $(0,60 \%)$. Grande parte da ração artesanal foi visualmente consumida pelos peixes antes mesmo de chegar ao fundo dos viveiros, mas os resultados indicam que houve eutroficação da água dos viveiros que a receberam. A ração tinha pouca ou nenhuma estabilidade na água e suas sobras contribuíram para a eutrofização.

\section{Conclusões}

1. O uso da ração artesanal à base de silagem de resíduo de filetagem de pescado para a criação de tilápia-do-nilo, em viveiros escavados, reduz em aproximadamente $42 \%$ o custo de arraçoamento, sem prejuízo para o desempenho produtivo.

2. As tilápias alimentadas com a ração artesanal apresentam menores teores de lipídios corporais.

3. O fornecimento da ração artesanal sem processamento piora a qualidade da água.

\section{Agradecimentos}

Aos professores Dalton José Carneiro e Antônio Fernando Monteiro Camargo, pelas análises realizadas nos Laboratórios de Nutrição de Organismos Aquáticos e de Ecologia Aquática do Centro de Aquicultura da Universidade Estadual Paulista.

\section{Referências}

ASSANO, M. Utilização de diferentes fontes e níveis de proteína no crescimento da tilápia do Nilo (Oreochromis niloticus). 2004. 35p. Dissertação (Mestrado) - Universidade Estadual Paulista, Jaboticabal.

ASSOCIATION OF OFFICIAL ANALYTICAL CHEMISTS. Official methods of analysis. Washington: AOAC, 2000.

BACCARIN, A.E.; CAMARGO, A.F.M. Characterization and evaluation of the impact of feed management on the effluents of Nile tilapia (Oreochromis niloticus) culture. Brazilian Archives of Biology and Technology, v.48, p.81-90, 2005.

BOSCOLO, W.R.; HAYASHI, C.; MEURER, F.; FEIDEN, A.; WOLFF, L. Desempenho e características de carcaça de tilápias do Nilo (Oreochromis niloticus L.) alimentadas com rações contendo diferentes níveis de gordura. Acta Scientiarum Animal Sciences, v.26, p.443-447, 2004.

BRASIL. Ministério do Meio Ambiente. Conselho Nacional do Meio Ambiente. Resolução no 357, de 17 março de 2005. Dispõe 
sobre a classificação dos corpos de água e diretrizes ambientais para o seu enquadramento, bem como estabelece as condições e padrões de lançamento de efluentes, e dá outras providências. Diário Oficial [da] República Federativa do Brasil, 18 de mar. 2005. p.58-63.

CARVALHO, G.G.P. de; PIRES, A.J.V.; VELOSO, C.M.; SILVA, F.F. da; CARVALHO, B.M.A. de. Silagem de resíduo de peixes em dietas para alevinos de tilápia-do-nilo. Revista Brasileira de Zootecnia, v.35, p.126-130, 2006.

CREMEN, M.C.M.; MARTINEZ-GOSS, M.R.; CORRE, V.L.; AZANZA, R.V. Phytoplankton bloom in commercial shrimp ponds using green-water technology. Journal of Applied Phycology, v.19, p.615-624, 2007.

DE ARRUDA, L.F.; BORGHESI, R.; OETTERER, M. Use of fish waste as silage - a review. Brazilian Archives of Biology and Technology, v.50, p.879-886, 2007.

EL-SAYED, A.F.M. Alternative dietary protein sources for farmed tilapia, Oreochromis spp. Aquaculture, v.179, p.149-168, 1999.

EL-SAYED, A.F.M.; TESHIMA, S. Protein and energy requirements of Nile tilapia, Oreochromis niloticus, fry. Aquaculture, v.103, p.55-63, 1992.

FAGBENRO, O.A.; JAUNCEY, K. Physical and nutritional properties of moist fermented fish silage pellets as a protein supplement for tilapia (Oreochromis niloticus). Animal Feed Science and Technology, v.71, p.11-18, 1998.

FIRETTI, R.; SALES, D.S. O futuro promissor da cadeia produtiva da piscicultura comercial. Anualpec, v.11, p.305-307, 2004.

FOOD AND AGRICULTURE ORGANIZATION OF THE UNITED NATIONS. The state of world fisheries and aquaculture. Rome: FAO, 2004.

GOLTERMAN, H.L.; CLYMO, R.S.; OHNSTAD, M.A.M. Methods for physical and chemical analysis of fresh waters. Oxford: Blackwell Scientific, 1978. 213p.

HAARD, N.F.; KARIEL, N.; HERZBERG, G.; FELTHAM, L.A.W.; WINTER, K. Stabilization of protein and oil in fish silage for use as a ruminant feed supplement. Journal of Science Food and Agriculture, v.36, p.229-241, 1985.

HASSAN, S.; EDWARDS, P.; LITTLE, D.C. Comparison of tilapia monoculture and carp polyculture in fertilized earthen ponds. Journal of the World Aquaculture Society, v.28, p.268274, 1997.

MACKERETH, F.J.H.; HERON, J.; TALLING, J.F. Water analysis: some revised methods for limnologist. Kendal: Titus Wilson \& Sans, 1978. 117p. (Freshwater Biological Association Scientifi c Publication, 36).

MCCAUSLAND, W.D.; MENTE, E.; PIERCE, G.J.; THEODOSSIOU, I. A simulation model of sustainability of coastal communities: aquaculture, fishing, environment and labour markets. Ecological Modelling, v.193, p.271-294, 2006.

MENDES, P.P. Estatística aplicada à aqüicultura. Recife: Bagaço, 1999. 265p.

MIRES, D. Aquaculture and the aquatic environment: mutual impact and preventive management. Israeli Journal of AquacultureBamidgeh, v.47, p.163-172, 1995.

MONTOYA, R.A.; LAWRENCE,A.L.; GRANT, W.E.; VELASCO, M. Simulation of phosphorus dynamics in an intensive shrimp culture system: effects of feed formulations and feeding strategies. Ecological Modelling, v.129, p.131-142, 2000.

NEW, M.B.; TACON, A.G.J.; CSAVAS, I. (Ed.). Farm-made aquafeeds. Rome: Food and Agriculture Organization of the United Nations, 1994. 434p. (FAO Fisheries Technical Paper, 343).

OLIVEIRA, M.M. de; PIMENTA, M.E. de S.G.; PIMENTA, C.J.; CAMARGO, A.C. da S.; FIORINI, J.E.; LOGATO, P.V.R. Digestibilidade e desempenho de alevinos de tilápia do Nilo (Oreochromis niloticus) alimentados com dietas contendo diferentes níveis de silagem ácida de pescado. Ciência e Agrotecnologia, v.30, p.1196-1204, 2006.

SAS INSTITUTE. Statistical analysis system. Versão 9. Cary: SAS Institute, 2002.

SILVA, M.A.F. O mercado para produtos industrializados da pesca e aqüicultura. In: WORKSHOP INTERNACIONAL DE AQÜICULTURA, 3., 1999, São Paulo. Anais. São Paulo: Gessulli Eventos, 1999. p.18-20.

SIPAÚBA-TAVARES, L.H.; ROCHA, O. Produção de plâncton (fitoplâncton e zooplâncton) para alimentação de organismos aquáticos. São Carlos: RiMa, 2003. 106p.

TATTERSON, I.N.; WINDSOR, M.L. Fish silage. Journal of the Science of Food and Agriculture, v.25, p.369-379, 1974.

TOLEDO, M.P.A. Processamentos de dietas práticas com diferentes fontes de energia para o crescimento e a digestibilidade da tilápia do Nilo. 2004. 79p. Tese (Doutorado) - Universidade Estadual Paulista, Jaboticabal.

VALENTI, W.C.; POLI, C.R.; PEREIRA, J.A.; BORGHETTI, J.R. Aqüicultura no Brasil: bases para um desenvolvimento sustentável. Brasília: CNPq, 2000. 399p.

WANG, Y.; LIU, Y.J.; TIAN, L.X.; DU, Z.Y.; WANG, J.T.; WANG, S.; XIAO, W.P. Effects of dietary carbohydrate level on growth and body composition of juvenile tilapia, Oreochromis niloticus $\mathrm{X}$ O. aureus. Aquaculture Research, v.36, p.1408-1413, 2005.

WINFREE, R.A.; STICKNEY, R.R. Effect of dietary protein and energy on growth, feed conversion efficiency and body composition of Tilapia aurea. Journal of Nutrition, v.111, p.1001-1012, 1981.

Recebido em 12 de janeiro de 2009 e aprovado em 31 de março de 2009 